\title{
Cardiopulmonary and Gas-Exchange Responses during the Six-Minute Walk Test in Patients with Chronic Obstructive Pulmonary Disease
}

\author{
Arnoldus J.R. van Gestel ${ }^{a}$ b $\quad$ Florent Baty $^{a} \quad$ Anne-Kathrin Rausch-Osthof ${ }^{b}$ \\ Martin H. Brutsche ${ }^{a}$ \\ ${ }^{a}$ Department of Pulmonary Medicine, Cantonal Hospital, St. Gallen, and ${ }^{b}$ Department of Health, Zurich University of \\ Applied Sciences, Winterthur, Switzerland
}

\section{Key Words}

Oxygen uptake kinetics $\cdot$ Six-minute walk test $\cdot$ Mobile cardiopulmonary monitoring · Submaximal exercise .

Cardiopulmonary exercise testing

\begin{abstract}
Background: The 6-min walk test (6MWT) is representative of daily life activities and reflects the functional capacity of patients with chronic obstructive pulmonary disease (COPD). Information on the cardiopulmonary and gas exchange responses to the 6MWT is limited. Objectives: We aimed to analyze the breath-by-breath cardiopulmonary and gas exchange responses of patients with COPD during the 6MWT. We also investigated the extent to which parameters reflecting cardiopulmonary and gas exchange function are associated with exercise capacity. Methods: The oxygen uptake $\left(\mathrm{VO}_{2}\right)$ kinetics of patients were obtained using mobile telemetric cardiopulmonary monitoring during a 6MWT. A new mean response time (MRT) index was developed to quantify $\mathrm{VO}_{2}$ on-kinetics by correcting MRT for work rate (wMRT). Multiple linear regression analysis was performed to assess the association between variables reflecting cardiopulmonary and gas exchange function and exercise capacity [6-min walking distance (6MWD) and $\mathrm{VO}_{2}$ at steady state $\left(\mathrm{VO}_{25 \mathrm{~s}}\right)$ ]. Results: In 72 COPD patients (29 fe-
\end{abstract}

\section{KARGER}

(C) 2014 S. Karger AG, Base

0025-7931/14/0884-0307\$39.50/0

E-Mail karger@karger.com

www.karger.com/res males) with a mean (SD) age of 65 (10) years, $\mathrm{FEV}_{1} 44(14) \%$ predicted exercise capacity as assessed by $\mathrm{VO}_{2 \mathrm{ss}}(\mathrm{p}=0.003)$ was significantly reduced across the stages of COPD. The criteria for maximal effort during the 6MWT were fulfilled by $82 \%$ of the patients. After adjustment for covariates, wMRT was independently associated with 6MWD $\left(p=9.7 \times 10^{-5}\right)$ and $\operatorname{VO}_{2 S s}\left(p=5.5 \times 10^{-10}\right)$. Conclusions: As wMRT mostly depends on the rate of increase of pulmonary blood flow, our results underline the fact that cardiocirculatory function may play a significant role in exercise tolerance in patients with COPD. Our findings imply that modification of cardiocirculatory function may be beneficial in the treatment of COPD patients and improve their outcome more than anticipated previously.

(c) 2014 S. Karger AG, Basel

\section{Introduction}

Chronic obstructive pulmonary disease (COPD) is associated with pronounced exercise intolerance resulting in an impaired health-related quality of life [1], greater health care requirements [2] and increased mor-

\section{A.J.R. van Gestel and F. Baty contributed equally to this article.}

Martin Brutsche, $\mathrm{MD}, \mathrm{PhD}$

Department of Pulmonary Medicine

Cantonal Hospital St. Gallen

CH-9002 St. Gallen (Switzerland)

E-Mail martin.brutsche@ kssg.ch 
tality [3]. Cardiopulmonary exercise testing (CPET) is used to identify the factors contributing to exercise intolerance by linking performance and physiological parameters to the underlying metabolic substratum in COPD patients [4]. It is routinely performed on a cycleergometer or motorized treadmill using a rapid ramped incremental protocol to the limit of tolerance [4]. Since most activities of daily living are performed in a nonincremental fashion and at a submaximal level of exertion, the 6-min walk test (6MWT) is representative of daily life activities and can therefore accurately reflect the functional capacity of patients [5].

The 6MWT is often used in clinical practice and research studies as it embodies an essential functional task and is inexpensive, reproducibile and responsive to standardization [4]. The classic 6MWT can only be used as a nonspecific assessment of functional capacity because cardiopulmonary and gas exchange responses to exercise cannot be determined with this test [6]. In particular, the assessment of the change in oxygen uptake $\left(\mathrm{VO}_{2}\right)$ in the initial phase of the 6MWT $\left(\mathrm{VO}_{2}\right.$ on-kinetics) may provide important information because most of the activities of daily living require a repetitive transition from rest to submaximal exercise intensity. In several chronic diseases, it has been demonstrated that $\mathrm{VO}_{2}$ on-kinetics have a higher prognostic value than peak $\mathrm{VO}_{2}$ [7]. An additional disadvantage of the classic $6 \mathrm{MWT}$ is that it cannot be used to identify factors contributing to exercise performance. Improved knowledge of the cardiopulmonary and gas exchange responses during the 6MWT may lead to a better understanding of the pathophysiological mechanisms causing functional impairments in patients with COPD.

To address the above-mentioned issues, we aimed to analyze the breath-by-breath cardiopulmonary and gas exchange responses of patients with COPD, i.e. with Global Initiative on Obstructive Lung Disease (GOLD) stages II-IV, during the 6MWT using mobile telemetric cardiopulmonary monitoring (MOB). We investigated the extent to which parameters reflecting cardiopulmonary and gas exchange function are associated with exercise capacity. Given the vast pathophysiological heterogeneity of exercise limitation in COPD, it may be reasonable to presume that the determinants of exercise capacity vary among patients. Furthermore, we investigated whether the 6MWT assesses the submaximal or maximal level of functional capacity in COPD patients.

\section{Material and Methods}

\section{Study Design}

We performed a cross-sectional, observational study on patients with COPD (GOLD stages II-IV). Patients referred to the Pulmonary Division of the University Hospital, Basel, Switzerland, between August 2003 and June 2007, were considered for participation in the study (fig. 1). Exclusion criteria were the need for oxygen supply or a resting transcutaneous oxygen saturation $\left(\mathrm{SpO}_{2}\right)$ of $<85 \%$ while breathing room air, an inability to walk, any acute coronary event during the previous month and conditions precluding the use of a face mask (e.g. an anatomic anomaly, claustrophobia or panic disorder). All patients gave their informed consent. Our local institutional review board approved the study. Some of the study population data were used in another study evaluating the feasibility, safety and clinical usefulness of a MOB-enhanced 6MWT [8].

\section{Six-Minute Walk Test}

All patients performed the 6MWT after pulmonary function testing. The 6-min walking distance (6MWD) was measured according to the guidelines of the American Thoracic Society (ATS) [9], with standardized encouragement [10], in a 30-meter corridor under supervision of an experienced technician. Before starting the $6 \mathrm{MWT}$, patients were to rest seated for 3-5 min until stable $\mathrm{VO}_{2}$ values had been recorded, i.e. $\mathrm{VO}_{2}$ at rest $\left(\mathrm{VO}_{2}\right.$ rest). The $6 \mathrm{MWT}$ was followed by a recovery phase, where the patient rested on a chair.

\section{MWT with the MOB Device}

Indirect calorimetry was performed using the Oxycon Mobile ${ }^{\circledR}$ (Viasys Healthcare, Conshohocken, Pa., USA) portable wireless CPET device in order to quantify breath-by-breath oxygen exchange kinetics during the 6MWT. Pulse rate was determined using an electrocardiogram-triggered belt (Polar T-61 ${ }^{\circledR}$, Polar Electro, Coxhoe, UK). $\mathrm{SpO}_{2}$ was measured using a finger clip. $\mathrm{VO}_{2}$ and carbon dioxide output $\left(\mathrm{VCO}_{2}\right)$, tidal volumes and breathing frequency were assessed using a face mask (dead space $<70 \mathrm{ml}$ ) with a flow sensor and a gas analyzer. The patient carried data storage and transfer units on a harness. Wireless transfer of breath-bybreath data to a laptop computer allowed real-time monitoring. The feasibility and safety of MOB had been tested in previous work by performing both $6 \mathrm{MWT}$ and MOB on consecutive days in random order [8]. The additional weight of the equipment $(950 \mathrm{~g}) \mathrm{had}$ no effect on the walking distance [8]. The exact 6MWT-MOB procedure has been described previously [8]. Exercise capacity was quantified by $6 \mathrm{MWD}$ and $\mathrm{VO}_{2}$ at steady state $\left(\mathrm{VO}_{2 \mathrm{SS}}\right)$.

\section{Exercise Limitation according to ATS Criteria}

The different types of exercise limitation were determined based on the ATS/American College of Chest Physicians Statement on CPET recommendations: 'the patients' effort was considered to be maximal if either one or more of the following criteria were fulfilled; ventilatory limitation: ventilatory reserve $<11$ liters or $<15 \%$; cardiocirculatory limitation: maximal heart rate $>90 \%$ predicted; gas exchange limitation: $\mathrm{VO}_{2}$ peak $>84 \%$ predicted' [4]. $\mathrm{VO}_{2}$ maximal predicted and maximal predicted heart rate (HR) were calculated using standard equations [11].

\section{Pulmonary Function}

Spirometry, whole-body plethysmography and diffusion capacity measurements were performed according to the ATS and European 
Respiratory Society guidelines with a commercially available system (Body 500 TM , ZAN, Oberthulba, Germany) [12, 13]. Postbronchodilator spirometry was performed on the same day as the 6MWTs.

Curve Fitting of $\mathrm{VO}_{2}$

Original breath-by-breath data were imported from the MOB device. Raw data were preprocessed by averaging the breath-bybreath measurements over consecutive periods of $30 \mathrm{~s}$. $\mathrm{VO}_{2}$ kinetics describe the rate of change in $\mathrm{VO}_{2}$ during exercise. Curves were fitted using the following nonlinear logistic regression model:

$$
\mathrm{VO}_{2}=\mathrm{c}+(\mathrm{d}-\mathrm{c}) /(1+\exp (\mathrm{b} \times(\text { time }-\mathrm{c})))
$$

with $\mathrm{b}$ representing the steepness of the curve, time - $\mathrm{c}$ representing $\mathrm{VO}_{2}$ rest, $\mathrm{d}$ representing $\mathrm{VO}_{2 \mathrm{SS}}$ and e representing the position of the inflection point.

\section{Mean Response Time Reparameterization}

Following the onset of constant workload exercise, the $\mathrm{VO}_{2}$ increase (i.e. on-kinetics) can be characterized by the time, i.e. the mean response time (MRT) required for $\mathrm{VO}_{2}$ to achieve $63 \%$ of the $\mathrm{VO}_{2 \mathrm{SS}}$ in response to physical stress. In this study, the MRT index was calculated to quantify $\mathrm{VO}_{2}$ on-kinetics by correcting MRT for work rate (wMRT) during the first phase of the 6MWT. This method has been described in work published previously [8]. The difference between $\mathrm{VO}_{2}$ rest and during effort $\left(\mathrm{VO}_{2 S \mathrm{~S}}-\mathrm{VO}_{2}\right.$ rest $)$ was used as a proxy for work rate during the first phase of the 6MWT.

\section{Statistical Data Analysis}

Descriptive data for continuous variables are expressed as a mean \pm SD, 95\% CI and percentages for frequencies. Variables were tested for parametric distribution by applying the ShapiroWilk test (null hypothesis rejection set at $\mathrm{p}<0.25$ ). Between-group differences of continuous variables were tested using linear models (ANOVA F test). Univariate linear regression was performed to assess the association between variables reflecting cardiopulmonary and gas exchange function and exercise capacity (6MWD and $\mathrm{VO}_{2 S \mathrm{~S}}$ ). Variables significantly associated with $6 \mathrm{MWD}$ and $\mathrm{VO}_{2 S \mathrm{~S}}$ in the univariate analysis were included in a multivariate analysis. Mixed-effect nonlinear regression was used to fit the $\mathrm{VO}_{2}$ curves. A p value of $<0.05$ was considered to indicate statistical significance. All the analyses were done using R statistical software [14], including the package drc for curve fitting [15] and medrc and nlme [16] for nonlinear mixed-effects modeling.

\section{Results}

\section{Patients' Characteristics}

Seventy-five patients with moderate to very severe COPD were included in our study. In 3 patients, curve fitting was unsatisfactory, leading to their exclusion from the analysis. Two distinct patterns of response to exercise were noticed in this group: in 2 patients, $\mathrm{VO}_{2}$ did not show a plateau, and in 1 patient, it showed a marked variability after reaching a plateau. Variable walking speed and pauses during the 6MWT are the most likely explanations for this observation. The exclusion process is depicted in figure 1.

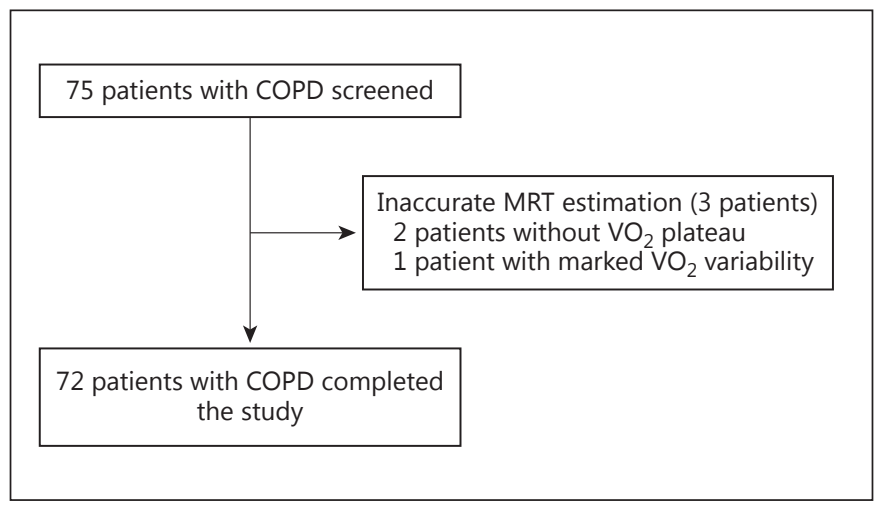

Fig. 1. Study synopsis.

Table 1. Anthropometrics, pulmonary function, respiratory symptoms and cardiopulmonary exercise capacity

\section{Variable}

\section{Anthropometrics}

Subjects, $\mathrm{n}$

Female/male

Age, years

BMI

$29 / 43$

$65.2 \pm 10.1$

$24.5 \pm 5.1$

Pulmonary function

$\mathrm{FEV}_{1}$, liters

$1.1 \pm 0.4$

$\mathrm{FEV}_{1}, \%$ predicted

$43.5 \pm 14.4$

$\mathrm{FEV}_{1} / \mathrm{IVC}$ ratio

$0.5 \pm 0.1$

DLCO, \% predicted

$51 \pm 23$

TLC, $\%$ predicted

$116 \pm 23$

RV/TLC ratio

$0.57 \pm 0.12$

Cardiopulmonary exercise capacity

6MWD, $\mathrm{m}$

$328.1 \pm 106.1$

$\mathrm{SpO}_{2}$ at rest, \%

$93.3 \pm 3.3$

$\mathrm{SpO}_{2}$ after exercise, \%

$82.6 \pm 7.2$

$\mathrm{SpO}_{2}$ at desaturation, \%

$8.4 \pm 6.5$

Dyspnea ${ }^{1}$ at rest, $0-10$

$1.0 \pm 1.1$

Dyspnea after exercise, $0-10$

$5.0 \pm 2.2$

Leg fatigue at rest, $0-10$

$0.4 \pm 0.4$

Leg fatigue after exercise, $0-10$

Values are presented as mean $\pm \mathrm{SD}$. DLCO = Diffusion capacity for carbon monoxide; $\mathrm{FEV}_{1} / \mathrm{IVC}$ ratio $=\mathrm{FEV}_{1}$ expressed as a $\%$ of IVC; RV/TLC = residual volume/TLC ratio; TLC $=$ total lung capacity. ${ }^{1}$ The rating of perceived exertion was assessed by the Borg scale, an 11-point scale (0-10).

Seventy-two patients were included in the final analysis. Data on their anthropometrical characteristics, lung function, respiratory symptoms and exercise capacity are presented in table 1. COPD was moderate (GOLD II) in $29.2 \%$ of the patients, severe (GOLD III) in $54.2 \%$ and very severe (GOLD IV) in $16.7 \%$. 


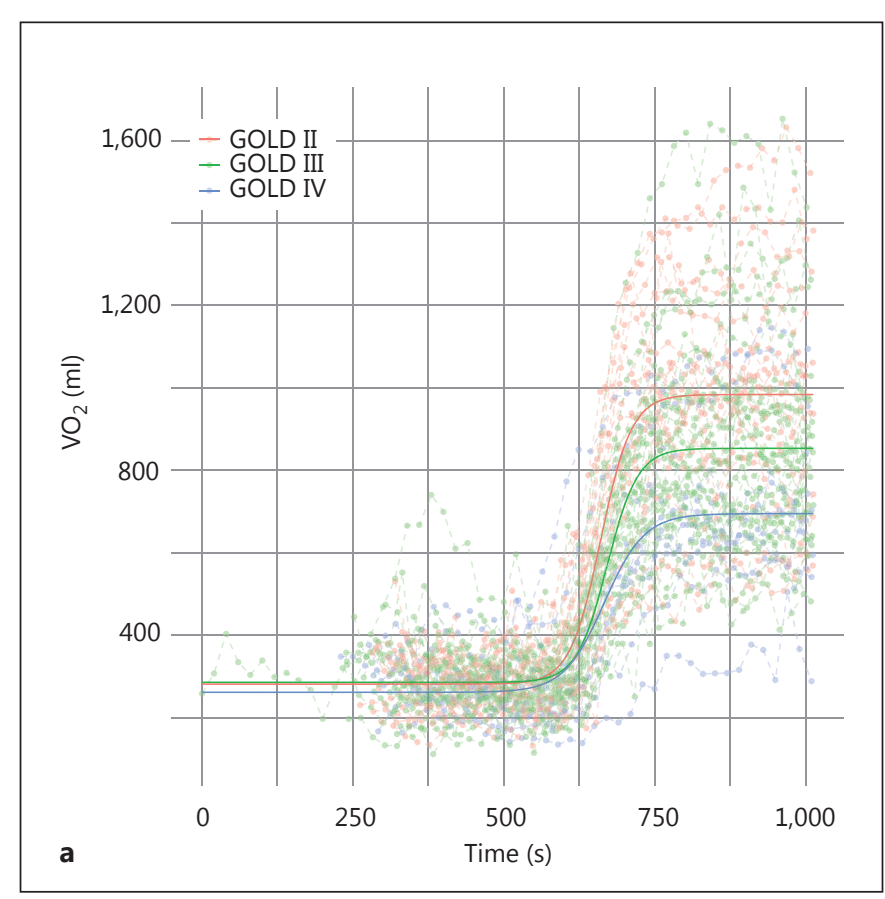

Fig. 2. a Curve fitting of $\mathrm{VO}_{2}$ for patients in GOLD stages II-IV. b The sigmoidal shapes of the $\mathrm{VO}_{2}$ curves of the patients in the different GOLD stages including prediction equations for $\mathrm{VO}_{2}$. At baseline, $\mathrm{VO}_{2}$ (i.e. $\mathrm{VO}_{2}$ rest) is different between the groups ( $\mathrm{p}=$

Exercise Capacity and $\mathrm{VO}_{2}$ Kinetics at Exercise Onset

Figure 2 shows the sigmoidal shapes of the $\mathrm{VO}_{2}$ curves of the patients at the different GOLD stages. At baseline, $\mathrm{VO}_{2}$ rest differs between groups $(\mathrm{p}=0.0024$; table 2$)$. The resting period of $5 \mathrm{~min}$ is followed by a period of rapid growth at exercise onset (the steepness of the curve), settling into $\mathrm{VO}_{2 \mathrm{Ss}}$ after $3 \mathrm{~min}$. Both the steepness of the curve $(\mathrm{p}=0.0302)$ and $\mathrm{VO}_{2 S S}(\mathrm{p}=0.0048)$ show highly significant differences between the GOLD stages. wMRT also shows highly significant differences between these GOLD stages $(\mathrm{p}=0.0013)$, with GOLD stage IV showing high wMRT values. $\mathrm{VO}_{2 \mathrm{SS}}$ was significantly $(\mathrm{p}=0.003)$ reduced across the stages of COPD (table 2).

\section{Exercise Limitation according to ATS Criteria}

Table 3 demonstrates that $81.9 \%$ of the patients with COPD reached the criteria for maximal effort as specified above, $59.7 \%$ had a ventilatory limitation, $12.5 \%$ had a cardiocirculatory limitation and $72.2 \%$ had a gas exchange limitation. Some patients fulfilled more than one criterion for maximal exercise.

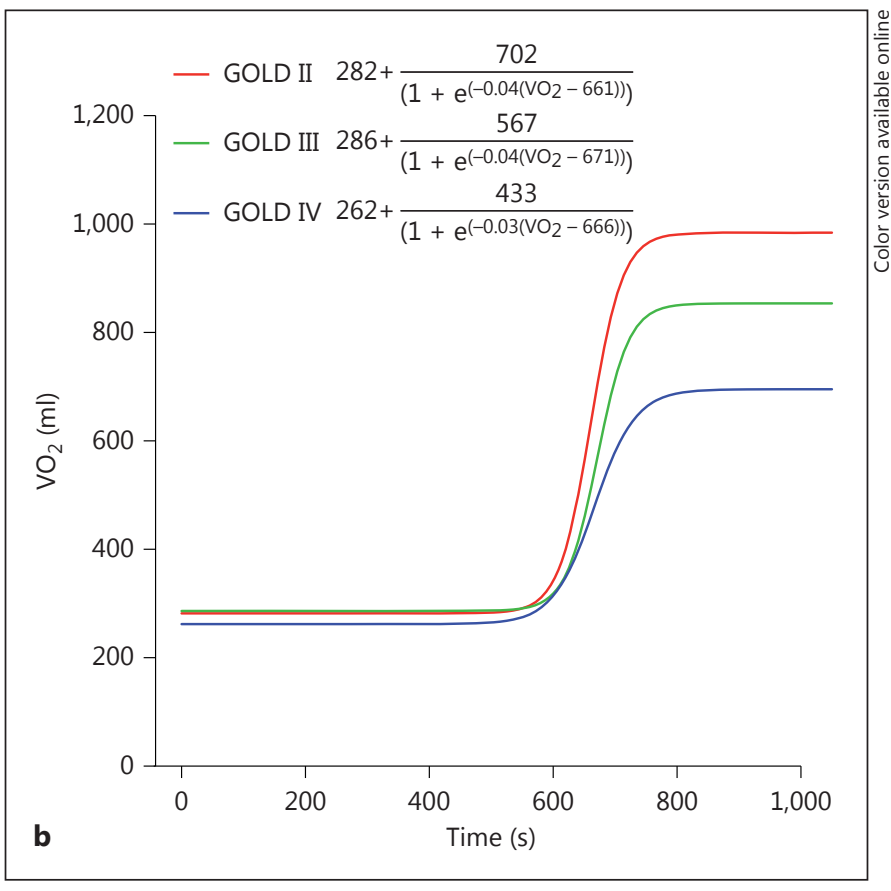

$0.0024)$. Both the steepness of the curve $(\mathrm{p}=0.0302)$ and $\mathrm{VO}_{2 \mathrm{SS}}$ $(\mathrm{p}=0.0048)$ show highly significant differences between GOLD stages II-IV.

\section{Determinants of Exercise Capacity}

The results of the univariate regression analysis are shown in table 4 . There was a significant association between exercise capacity (6MWD), $\mathrm{FEV}_{1}$ and wMRT. Exercise capacity as quantified by $\mathrm{VO}_{2 S S}$ was associated with BMI, $\mathrm{FEV}_{1}, \mathrm{FVC}, \mathrm{HR}$, dyspnea and wMRT. After adjusting for covariates in multiple regression analyses (table 5), wMRT was found to be independently associated with $6 \mathrm{MWD}$ and $\mathrm{VO}_{2 \mathrm{Ss}}$. We found no independent association with dyspnea. There was a significant association between $\mathrm{SpO}_{2}$ at rest and 6MWD.

\section{Discussion}

The purpose of this study was to gain insights into the cardiopulmonary and gas exchange responses of patients with COPD in the different GOLD stages during the $6 \mathrm{MWT}$. The $\mathrm{VO}_{2}$ curves of the patients with different GOLD stages all have sigmoidal shapes. Patients with advanced airflow limitation (higher GOLD stages) have altered $\mathrm{VO}_{2}$ kinetics during the transition from rest to work (wMRT) as well as a lower exercise capacity $\left(\mathrm{VO}_{2 \mathrm{SS}}\right)$. 
Table 2. Characteristics of participants, grouped into 3 categories according to GOLD stage

\begin{tabular}{lcccc}
\hline & GOLD II & GOLD III & GOLD IV & p value \\
\hline Number of patients & 21 & 39 & 12 & \\
Sex, female & 10 & 14 & 5 & 0.050 \\
Age, years & $67.3 \pm 11.6$ & $66.0 \pm 7.6$ & $20.8 \pm 12.7$ & $<0.001$ \\
BMI & $28.3 \pm 5.5$ & $23.7 \pm 4.2$ & $0.7 \pm 0.1$ & $<0.001$ \\
FEV, l/s & $1.5 \pm 0.4$ & $1.0 \pm 0.2$ & $2.1 \pm 0.4$ & 0.049 \\
FVC, liters & $2.8 \pm 0.9$ & $2.6 \pm 0.8$ & $0.4 \pm 0.1$ & $<0.001$ \\
FEV $/$ FVC & $0.6 \pm 0.1$ & $0.4 \pm 0.1$ & $677.7 \pm 203.2$ & 0.003 \\
VO 2Ss, ml/min & $986.0 \pm 268.4$ & $844.7 \pm 235.8$ & $-0.030 \pm 0.0027$ & 0.0302 \\
b (steepness of the curve) & $-0.039 \pm 0.0018$ & $-0.039 \pm 0.0016$ & $261.9 \pm 6.4$ & 0.0024 \\
c (lower asymptote) & $281.8 \pm 4.4$ & $286.2 \pm 3.3$ & $695.2 \pm 69.7$ & 0.0048 \\
d (upper asymptote) & $984.0 \pm 50.5$ & $853.6 \pm 38.0$ & $275.5 \pm 133.0$ & 0.093 \\
Walking distance, $\mathrm{m}$ & $359.1 \pm 110.2$ & $327.5 \pm 90.1$ & $5.0 \pm 2.4$ & 0.112 \\
Dyspnea (Borg scale) & $4.2 \pm 1.8$ & $5.4 \pm 2.3$ & $1.51 \pm 0.69$ & 0.075 \\
MRT, min & $1.16 \pm 0.42$ & $1.19 \pm 0.41$ & $6.86 \times 10^{-3}$ & 0.0013 \\
wMRT, min ${ }^{2} /$ ml & $1.99 \times 10^{-3}$ & $2.56 \times 10^{-3}$ & $\pm 10.88 \times 10^{-3}$ & \\
& $\pm 1.19 \times 10^{-3}$ & $\pm 1.59 \times 10^{-3}$ & & \\
\hline
\end{tabular}

Data are presented as mean $\pm \mathrm{SD} . \mathrm{FEV}_{1} / \mathrm{FVC}$ ratio $=\mathrm{FEV}_{1}$ expressed as a $\%$ of FVC.

The criteria for maximal effort during the $6 \mathrm{MWT}$ were fulfilled by $81.9 \%$ patients. After adjusting for covariates in the multiple regression analyses, wMRT was found to be independently associated with both 6MWD and $\mathrm{VO}_{2 s s}$.

There is some debate in the literature as to whether the $6 \mathrm{MWT}$ in patients with COPD reflects maximal [17, $18]$ or submaximal $[19,20]$ sustainable exercise. Troosters et al. [19] compared the physiological responses of 20 patients with COPD during an encouraged 6MWT and maximal-cycle ergometer exercise testing. They demonstrated that encouraged 6MWT (in the 4th-6th min) and peak cycling showed identical $\mathrm{VO}_{2}$ responses and similar $\mathrm{HR}$ responses. As the $\mathrm{VCO}_{2}$ and ventilatory response were found to be lower during walking than at peak cycling, it was concluded that the 6MWT should be referred to as submaximal. Hill et al. [21] compared the peak and submaximal cardiopulmonary responses to the $6 \mathrm{MWT}$ with a ramp-cycle ergometer test in 24 patients with moderate COPD. In accordance with the results of Troosters et al. [19], they demonstrated that the 6MWT elicited a similar peak rate of $\mathrm{VO}_{2}$ and $\mathrm{HR}$ as a cycle ergometer test. Turner et al. [22] observed similar peak exercise responses achieved in the 6MWT and CPET in 20 patients with moderate to severe COPD. Controversially, van Helvoort et al. [20] found that $\mathrm{VO}_{2}$ and $\mathrm{HR}$ were lower after the $6 \mathrm{MWT}$ than at peak cycling. According to the ATS criteria [4] for the determination of test in-
Table 3. Exercise limitations according to ATS criteria

\begin{tabular}{lr}
\hline Limitations & Patients, $\mathrm{n}(\%)$ \\
\hline Ventilatory & $43 / 72(59.7 \%)$ \\
Cardiocirculatory & $9 / 72(12.5 \%)$ \\
Gas exchange & $52 / 72(72.2 \%)$ \\
At least one limitation & $59 / 72(81.9 \%)$ \\
\hline
\end{tabular}

ATS criteria for the determination of test intensity were applied [9]. The effort was considered to be maximal if $\geq 1$ of the following criteria were fulfilled: ventilatory limitation, i.e. ventilatory reserve $<11$ liters or $<15 \%$, cardiocirculatory limitation, i.e. maximal heart rate $>90 \%$ predicted and gas exchange limitation, i.e. $\mathrm{VO}_{2}$ peak $>84 \%$ predicted.

tensity, $81.9 \%$ of our patients reached at least one limitation; this being a substantial number, the $6 \mathrm{MWT}$ could be considered as maximal sustainable exercise.

The multifactorial character of exercise limitation in patients with COPD was underlined by the fact that our patients experienced ventilatory, cardiocirculatory and/ or gas exchange limitations. The number of patients who experienced one or more limitations is compelling and provides a rationale that, at least in some patients, exercise capacity is limited by several mechanisms as well as that a single mechanism does not necessarily dominate in every single patient. 
Table 4. Determinants of exercise capacity

\begin{tabular}{|c|c|c|c|c|c|c|}
\hline & \multicolumn{3}{|l|}{ 6MWD } & \multicolumn{3}{|l|}{$\mathrm{VO}_{2 \mathrm{SS}}$} \\
\hline & estimate & SE & $\mathrm{p}$ value & estimate & SE & $\mathrm{p}$ value \\
\hline Age, years & -0.75 & 1.25 & 0.5485 & 2.64 & 3.06 & 0.391629 \\
\hline BMI & 2.63 & 2.47 & 0.2911 & 27.32 & 4.97 & $6.43 \times 10^{-7 * * *}$ \\
\hline $\mathrm{FEV}_{1}, \mathrm{l} / \mathrm{s}$ & 61.31 & 30.88 & 0.05099 & 266.13 & 69.00 & $0.00026^{* * *}$ \\
\hline $\mathrm{FEV}_{1}, \%$ predicted & 1.99 & 0.84 & $0.02153^{*}$ & 6.42 & 1.99 & $0.00195^{* *}$ \\
\hline FVC, liters & 20.78 & 15.28 & 0.1781 & 101.88 & 35.31 & $0.005277^{* *}$ \\
\hline HR max, bpm & 0.72 & 0.61 & 0.24638 & 3.49 & 1.44 & $0.01831^{* *}$ \\
\hline HR reserve, bpm & -0.50 & 0.60 & 0.4044 & -3.81 & 1.37 & $0.007029^{* *}$ \\
\hline HR rest, bpm & -1.76 & 0.83 & $0.03811^{*}$ & -2.50 & 2.18 & 0.2565 \\
\hline $\mathrm{SpO}_{2} \max , \%$ & 11.45 & 3.65 & $0.00249^{* *}$ & 11.93 & 9.21 & 0.1997 \\
\hline $\mathrm{SpO}_{2} \min , \%$ & 2.14 & 1.74 & 0.2241 & 2.22 & 4.20 & 0.5993 \\
\hline VE reserve, $1 / \mathrm{min}$ & 0.29 & 1.01 & 0.7718 & 0.52 & 2.46 & 0.8327 \\
\hline $\mathrm{wMRT}, \mathrm{min}^{2} / \mathrm{ml}$ & $-9,913.28$ & $2,395.73$ & $9.74 \times 10^{-5 * * *}$ & $-117,278.42$ & $16,146.35$ & $5.5 \times 10^{-10 *}$ \\
\hline $\mathrm{VE}$ rest, $1 / \mathrm{min}$ & -1.81 & 2.97 & 0.5450 & 13.28 & 7.010 & 0.06557 \\
\hline $\mathrm{VO}_{2}$ rest & 0.024 & 0.12 & 0.8434 & 0.86 & 0.28 & $0.003091^{* *}$ \\
\hline Dyspnea (Borg scale) & -7.385 & 14.250 & 0.606 & -16.375 & 5.570 & $0.004^{* *}$ \\
\hline
\end{tabular}

$\mathrm{SE}=$ Standard error; $\mathrm{SpO}_{2} \max =\mathrm{SpO}_{2}$ at rest; $\mathrm{SpO}_{2} \min =\mathrm{SpO}_{2}$ at the end of $6 \mathrm{MWT} ; \mathrm{VE}=$ mean ventilation. ${ }^{*} 0.01 \leq \mathrm{p}<0.05$. ${ }^{* *} 0.001 \leq \mathrm{p}<0.01$. $^{* *} \mathrm{p}<0.001$.

Table 5. Predictors of exercise capacity

6MWD

\begin{tabular}{lclrl}
\hline & Estimate & $\mathrm{SE}$ & $\mathrm{t}$ value & $\mathrm{p}$ value \\
\hline Intercept & -490.82 & 348.66 & -1.41 & 0.163904 \\
$\mathrm{SpO}_{2} \mathrm{max}, \%$ & 8.87 & 3.57 & 2.48 & $0.015586^{*}$ \\
$\mathrm{HR} \mathrm{reserve,} \mathrm{bpm}$ & -0.12 & 0.85 & -0.14 & 0.887210 \\
$\mathrm{FEV}_{1}, \% \mathrm{predicted}$ & 0.65 & 0.86 & 0.75 & 0.457409 \\
$\mathrm{wMRT}_{\mathrm{min}} / \mathrm{ml}$ & $-8,563.08$ & $2,453.14$ & -3.49 & $0.000864^{* * *}$ \\
\hline
\end{tabular}

$\mathrm{VO}_{2 \mathrm{SS}}$

\begin{tabular}{lclcl}
\hline & Estimate & $\mathrm{SE}$ & $\mathrm{t}$ value & $\mathrm{p}$ value \\
\hline Intercept & $8.17 \times 102$ & $1.16 \times 10$ & 7.028 & $1.79 \times 10^{-9 * * *}$ \\
HR reserve, bpm & -1.69 & 1.03 & -1.65 & 0.1040 \\
$\mathrm{VO}_{2}$ rest & $4.69 \times 10^{-1}$ & $2.14 \times 10^{-1}$ & 2.19 & $0.0321^{*}$ \\
$\mathrm{FEV}_{1}$, liters & $1.744 \times 10^{2}$ & $5.41 \times 10^{1}$ & 3.23 & $0.0020^{* *}$ \\
${\text { wMRT, } \mathrm{min}^{2} / \mathrm{ml}}_{\text {Dyspnea (Borg scale) }}^{-8.68 \times 10^{4}}$ & $1.64 \times 10^{4}$ & -5.31 & $1.53 \times 10^{-6 * * *}$ \\
\hline
\end{tabular}

$\mathrm{SE}=$ Standard error; $\mathrm{SpO}_{2}$ max $=$ oxygen saturation at rest.

${ }^{*} 0.01 \leq \mathrm{p}<0.05$. ${ }^{* *} 0.001 \leq \mathrm{p}<0.01{ }^{* * *} \mathrm{p}<0.001$.

There is growing interest in submaximal exercise parameters capable of objectively evaluating the functional capacity of patients with COPD. As $\mathrm{VO}_{2}$ on-kinetics provide information about oxygen delivery and muscle me- tabolism, they have proved to be very successful in reflecting functional capacity in several studies [23, 24]. In addition, assessing $\mathrm{VO}_{2}$ on-kinetics is clinically relevant because they are influenced only by the underlying disease, not by the patient's motivation or the criteria used to terminate the test [25]. It has been recently demonstrated that $\mathrm{VO}_{2}$ on-kinetics of patients with COPD are slowed when compared to healthy age-matched controls $[26,27]$. In this study, $\mathrm{VO}_{2}$ on-kinetics (wMRT) and exercise capacity as assessed by $\mathrm{VO}_{2 S S}$ were significantly reduced across the stages of COPD.

Furthermore, we found that $\mathrm{VO}_{2}$ on-kinetics (wMRT) were independently associated with exercise capacity. At the onset of exercise, oxygen kinetics mostly depend on the rate of increase of pulmonary blood flow [28]. The increase in cardiac output at the onset of exercise predominantly depends on the increase in stroke volume. As patients with COPD exhibit impairment in the distensibility and vasodilatory capacity and a reduction in size of the pulmonary vascular bed, the capacity for stroke volume to augment cardiac output is limited [29,30]. In accordance with our results, Watz et al. [29] demonstrated that impaired left ventricular diastolic filling was independently associated with reduced exercise tolerance. Although it has been postulated that exercise capacity in patients with COPD is predominantly associated with the combination 
of increased ventilatory requirements (mainly secondary to increased ventilation/perfusion mismatching) and acute derangements in dynamic ventilatory mechanics [31], the results of our study underline the role of diminished stroke volume on exercise intolerance.

Our findings suggest that modification of cardiocirculatory function may be beneficial in the treatment of COPD patients and improve their outcome more than previously anticipated.

\section{Study Limitations}

It should be stressed that a causal relationship cannot be established from a cross-sectional study. In addition, the number of subjects was low, given the variance in data. Future data from controlled trials are needed to assess the impact of cardiocirculatory function on exercise capacity in patients with COPD. Another limiting factor was the fact that MRT could not be calculated in all patients. Some patients were unable to perform the 6MWT with a constant walking speed or without interruptions, which could explain the marked variability in $\mathrm{VO}_{2}$ in patients in whom curve fitting failed. Those patients whose $\mathrm{VO}_{2}$ did not reach a plateau probably increased their walking speed during the 6MWT, thereby increasing work rate.

\section{Conclusions}

The cardiopulmonary and gas exchange responses of patients with COPD during the $6 \mathrm{MWT}$ demonstrate an alteration in $\mathrm{VO}_{2}$ on-kinetics and a reduced exercise capacity across the GOLD stages. Most patients with COPD fulfilled the criteria for maximal effort during the 6MWT. After adjustment for covariates, wMRT was independently associated with $6 \mathrm{MWD}$ and $\mathrm{VO}_{2 \mathrm{ss}}$.

\section{References}

1 Jones PW: Activity limitation and quality of life in COPD. COPD 2007;4:273-278.

-2 Garcia-Aymerich J, Lange P, Benet M, et al: Regular physical activity reduces hospital admission and mortality in chronic obstructive pulmonary disease: a population-based cohort study. Thorax 2006;61:772-778.

-3 Cote CG, Pinto-Plata V, et al: The 6-min walk distance, peak oxygen uptake, and mortality in COPD. Chest 2007;132:1778-1785.

4 American Thoracic Society/American College of Chest Physicians: ATS/ACCP Statement on cardiopulmonary exercise testing. Am J Respir Crit Care Med 2003;167:211277.

5 Spruit MA, Polkey MI, Celli B, Edwards LD, Watkins ML, et al: Predicting outcomes from 6-minute walk distance in chronic obstructive pulmonary disease. J Am Med Dir Assoc 2011;13:291-297.

6 Poole-Wilson PA: The 6-minute walk: a simple test with clinical application. Eur Heart J 2000;21:507-508.

7 Poole DC, Hirai DM, Copp SW, Musch TI: Muscle oxygen transport and utilization in heart failure: implications for exercise (in)tolerance. Am J Physiol Heart Circ Physiol 2012; 302:1050-1063.

-8 Tueller C, Kern L, Azzola A, Baty F, Condrau $S$, Wiegand J, et al: Six-minute walk test enhanced by mobile telemetric cardiopulmonary monitoring. Respiration 2010;80:410418.
-9 American Thoracic Society: Guidelines for the six-minute walk test. Am J Respir Care Med 2002;166:111-117.

10 Guyatt GH, Pugsley SO, Sullivan MJ, Thompson PJ, Berman L, Jones NJ: Effect of encouragement on walking test performance. Tho$\operatorname{rax} 1984 ; 39: 818-822$.

11 Fairbarn MS, Blackie SP, McElvaney NG, Wiggs BR, Paré PD, Pardy RL: Prediction of heart rate and oxygen uptake during incremental and maximal exercise in healthy adults. Chest 1994;105:1365-1369.

12 Miller MR, Hankinson J, Brusasco V, Burgos F, Casaburi R, Coates A, et al: Standardisation of spirometry. Eur Respir J 2005;26:319-338.

13 Miller MR, Crapo R, Hankinson J, Brusasco V, Burgos F, Casaburi R, Coates A, Enright P, van der Grinten $\mathrm{CP}$, Gustafsson P, Jensen R, Johnson DC, MacIntyre N, McKay R, Navajas D, Pedersen OF, Pellegrino R, Viegi G, Wanger J: General considerations for lung function testing. Eur Respir J 2005;26:153161.

14 R Development Core Team: R: A Language and Environment for Statistical Computing. Vienna, R Foundation for Statistical Computing, 2009.

15 Ritz C, Streibig JC: Bioassay analysis using R. J Stat Softw 2005;12:1-22.

16 Pinheiro J, Bates D, DebRoy S, Sarkar D; R Core Team: Manual Linear and Nonlinear Mixed Effects Models 2013 (R package version 3.1-113).
17 Casas, A, Vilaro, J, Rabinovich, R, et al: Encouraged 6-min walking test indicates maximum sustainable exercise in COPD patients. Chest 2005;128:55-61.

18 Onorati P, Antonucci R, Valli G, Berton E, De Marco F, Serra P, Palange P: Non-invasive evaluation of gas exchange during a shuttle walking test vs. a 6-min walking test to assess exercise tolerance in COPD patients. Eur J Appl Physiol 2003;89:331-336.

19 Troosters T, Vilaro J, Rabinovich R, Casas A, Barbera JA, Rodriguez-Roisin R, Roca J: Physiological responses to the 6-min walk test in patients with chronic obstructive pulmonary disease. Eur Respir J 2002;20:564.

20 van Helvoort HA, Heijdra YF, de Boer RC, Swinkels A, Thijs HM, Dekhuijzen PN: Sixminute walking-induced systemic inflammation and oxidative stress in muscle-wasted COPD patients. Chest 2007;131:439-445.

21 Hill K, Dolmage TE, Woon L, Coutts D, Goldstein R, Brooks D: Comparing peak and submaximal cardiorespiratory responses during field walking tests with incremental cycle ergometry in COPD. Respirology 2012;17:278284.

-22 Turner SE, Eastwood PR, Cecins NM, Hillman DR, Jenkins SC: Physiologic responses to incremental and self-paced exercise in COPD: a comparison of three tests. Chest 2004;126: 766-773. 
23 Puente-Maestu L, Sanz ML, Sanz P, Nunez A, Gonzalez F, Whipp BJ: Reproducibility of the parameters of the on-transient cardiopulmonary responses during moderate exercise in patients with chronic obstructive pulmonary disease. Eur J Appl Physiol 2001;85:434-441.

24 Hughson RL: Oxygen uptake kinetics: historical perspective and future directions. Appl Physiol Nutr Metab 2009;34:840-850.

25 Janicki JS, Gupta S, Ferris ST, et al: Long-term reproducibility of respiratory gas exchange measurements during exercise in patients with stable cardiac failure. Chest 1990;97:1217.
26 Chiappa GR, Borghi-Silva A, Ferreira LF, Carrascosa C, Oliveira CC, Maia J, Gimenes AC, Queiroga F Jr, Berton D, Ferreira EM, Nery LE, Neder JA: Kinetics of muscle deoxygenation are accelerated at the onset of heavyintensity exercise in patients with COPD: relationship to central cardiovascular dynamics. J Appl Physiol 2008;104:1341-1350.

27 Borghi-Silva A, Beltrame T, Reis MS, Sampaio LMM, Catai AM, Arena R, et al: Relationship between oxygen consumption kinetics and BODE Index in COPD patients. Int J Chron Obstruct Pulmon Dis 2012;7:711-718.

28 Kemps HM, Schep G, Hoogsteen J, Thijssen EJ, De Vries WR, Zonderland M, Doevendans P: Oxygen uptake kinetics in chronic heart failure: clinical and physiological aspects. Neth Heart J 2009;17:238-244.
29 Watz H, Waschki B, Meyer T, Kretschmar G, et al: Decreasing cardiac chamber sizes and associated heart dysfunction in COPD: role of hyperinflation. Chest 2010;138:32-38.

30 Barr RG, Bluemke DA, Ahmed FS, et al: Percent emphysema, airflow obstruction, and impaired left ventricular filling. N Engl J Med 2010;362:217-227.

31 O'Donnell DE, Webb KA: Exertional breathlessness in patients with chronic airflow limitation: the role of lung hyperinflation. Am Rev Respir Dis 1993;148:1351-1357. 